\title{
Elaboração de textos de divulgação científica e sua avaliação por alunos de Licenciatura em Química
}

\author{
Production and evaluation of science communication texts by \\ undergraduate chemistry students in teacher training courses
}

\author{
Verenna Barbosa Gomes, Roberto Ribeiro da Silva e Patrícia Fernandes Lootens Machado
}

\begin{abstract}
Resumo: Os textos de divulgação científica têm sido discutidos na literatura como recurso didático complementar ao ensino formal. Pesquisas realizadas relativas a essa temática mencionam que são poucos os trabalhos que relacionam a elaboração desses textos e seu uso em cursos superiores e de licenciatura. Considerando essa questão, o objetivo da presente pesquisa foi elaborar textos de divulgação científica, tendo como eixos norteadores a experimentação, a história e a natureza da ciência e aspectos da interface CTSA. Os textos buscaram atender a três categorias essenciais: o tema, o estilo e a composição. Um segundo objetivo foi investigar a aplicação desses textos junto aos alunos de licenciatura em Química. Os dados foram analisados segundo três vertentes: a primeira refere-se à avaliação na categoria forma; a segunda, à avaliação na categoria conteúdo; e a terceira, à avaliação quanto à utilização de textos de divulgação científica no ensino. Os resultados mostraram que os eixos norteadores estabelecidos deram características específicas aos textos, possibilitando estratégias de sua utilização em cursos de licenciatura. Os dados também confirmam outras pesquisas apresentadas na literatura quanto às lacunas na formação inicial de professores referentes à natureza da Ciência e ao papel da experimentação no ensino.
\end{abstract}

Palavras-chave: ensino de Química, divulgação científica, abordagem CTSA, dialogicidade, interdisciplinaridade

\begin{abstract}
Science communication texts have been discussed in the literature as a teaching resource, complementary to formal education. Studies on this subject mention that few papers link the elaboration of such texts to their use in undergraduate courses. Considering this issue, we have developed science communication texts having as guiding principles experimentation, history and nature of science and aspects of STSE interface. Three essential categories were considered in the writing of the texts: topic, style and composition. A second goal was to analyze the use of the texts with undergraduate Chemistry students. Data were analyzed according to three criteria: evaluation of the format of the texts; evaluation of the content of the texts; and evaluation of the use of science communication texts in teaching. Data demonstrate that the preset guiding principles provided the texts with specific characteristics, which made it possible to develop strategies for their use in teacher training. Data also confirm other published researches regarding gaps in initial teacher training concerning the nature of science and the role of experimentation in science education.
\end{abstract}

Keywords: Chemistry teaching, science communication, STSE approach, dialogicity, interdisciplinarity,

\footnotetext{
Verenna Barbosa Gomes (verennabg1 @ gmail.com), licenciada em Química pela Universidade Estadual de Santa Cruz (UESC), mestre em Ensino de Química pela Universidade de Brasília (UnB), docente da Universidade Federal de Tocantins (UFT) - Campus Araguaína, aluna do Programa de Pós-Graduação em Educação em Ciências da Universidade de Brasília. Brasília, DF - BR. Roberto Ribeiro da Silva (bobsilva@ unb.br), bacharel em Química pela Universidade Federal de Minas Gerais (UFMG), doutor em Química pela Universidade de São Paulo (USP, São Paulo), Professor Colaborador Sênior da Universidade de Brasília (UnB). Brasília, DF - BR. Patrícia Fernandes Lootens Machado (pflmachado@ gmail.com), bacharel em Química pela Universidade Federal do Ceará, mestre e doutora em Engenharia pela Universidade Federal do Rio Grande do Sul (UFRGS), docente da Universidade de Brasília (UnB). Brasília, DF - BR. Recebido em 11/03/2015, aceito em 15/04/2016
}

A seção "Cadernos de Pesquisa" é um espaço dedicado exclusivamente para artigos inéditos (empíricos, de revisão ou teóricos) que apresentem profundidade teórico-metodológica, gerem conhecimentos novos para a área e contribuições para o avanço da pesquisa em Ensino de Química. 
A sociedade atual é marcada pelo notório e acelerado desenvolvimento científico e tecnológico, do qual resulta elevada produção de conhecimento. Os constantes avanços e aplicações desse conhecimento interferem no modo de vida da humanidade. Sendo assim, como forma de democratização do saber, todo cidadão tem o direito à informação. No entanto, somente acessar a informação não é suficiente. Há que se possibilitar a cada indivíduo, mesmo que não faça parte do meio científico-tecnológico, avaliar, comparar, enfrentar e ressignificar o conhecimento. Essas são algumas das razões para que o conhecimento produzido pela academia não fique restrito ao seu espaço esotérico, sendo compreendido como um direito dos cidadãos, defendido desde 1948 na Declaração Universal dos Direitos Humanos divulgada pela Organização das Nações Unidas (ONU).

A divulgação do conhecimento científico também pode contribuir para que os cidadãos compreendam como a ciência se desenvolve, quais as ferramentas necessárias para isso e quais impactos podem ser gerados com a aplicação do conhecimento. Dessa forma, a população passa a ter maior autonomia para legitimar ou não o investimento de recursos nessa área (ESTRADA, 2011).

Nessa perspectiva, o acesso à informação sobre ciência é potencialmente defendido na literatura por diferentes autores (CINI, 1998; CARNEIRO, 2009; MOREIRA, 2006), tornando a Divulgação Científica (DC) um tema de grande relevância no século atual.

Evidentemente, existem diferentes esferas sociais, que, por sua vez, demandam distintos graus de compreensão do discurso da Divulgação Científica. Ao se pensar, por exemplo, nos reflexos dos avanços da ciência e da tecnologia sobre os adolescentes, vislumbra-se o compromisso educativo da Divulgação Científica na esfera escolar.

Ao deslindar o papel da escola e as suas tendências pedagógicas na contemporaneidade, defende-se aqui a sala de aula como um espaço com diferentes possibilidades de significados sobre a ciência e o seu papel na sociedade, a partir da divulgação científica. Mais especificamente, o ensino de Química parece-nos possibilitar, no contexto da divulgação/ compreensão da ciência, a formação do sujeito social.

Mas que contribuições efetivas a DC tem dado ao campo de Ensino de Química? E que estratégias podem se utilizar para mensurar as suas potencialidades?

Outras questões emergentes sobre a realidade atual do século XXI permeiam este manuscrito. De que forma os avanços da ciência têm refletido no modo da vida da humanidade? Como estamos vivendo diante dos inúmeros avanços em tão curto espaço de tempo? Como se dão as relações espaço, tempo, sociedade, educação versus ciência? Como a escola, enquanto espaço de inclusão social e de formação de cidadãos, pode mediar essas relações?

Cabe aos professores estabelecer a ponte entre os Textos de Divulgação da Ciência (TDC) e os conteúdos a serem trabalhados na sala de aula. Mas como fazê-lo se, durante a formação inicial, poucos dos futuros professores de Química têm a oportunidade de refletir e traçar metodologias quanto ao uso de um TDC? As pesquisas de Nascimento e Junior (2010) apontam que "poucos estudos têm refletido sobre as possibilidades de discussão - no âmbito de formação inicial - de aspectos relacionados a textos de Divulgação Científica, tampouco sobre como se dariam as interações discursivas entre os futuros professores e os respectivos textos".

Inserir o contexto da formação do professor parece ser o melhor caminho para abordar alguns dos questionamentos acima. Logo, o fato gerador dessa pesquisa está voltado para a quase ausência da Divulgação Científica, especificamente a produção de textos dessa natureza, na formação inicial de professores de Química. Os professores não usam Textos de Divulgação Científica, pois consideram que os mesmos não acompanham o currículo (STRACK et al., 2009).

Esta pesquisa emergiu da percepção da necessidade de incluir, na formação inicial do professor, atividades relacionadas à divulgação da ciência. Além disso, foi motivada pela linha de investigação centrada na utilização de Textos de Divulgação Científica no Ensino das Ciências. Se, por um lado, essa linha de investigação discute as potencialidades dos TDC para as aprendizagens dos alunos em ciências, por outro, ela evidencia as dificuldades dos professores em compreender a dimensão metodológica desse material nas suas práticas pedagógicas.

Acreditamos que, ao introduzir nos textos de divulgação da ciência aspectos das relações entre Ciência, Tecnologia, Sociedade e Ambiente, da história e natureza da ciência e da experimentação, isso poderá aumentar o interesse dos professores quanto à utilização desse material.

Tendo em vista esse contexto, o objetivo da presente pesquisa foi elaborar Textos de Divulgação Científica (TDC), tendo como eixos norteadores a experimentação, a história e a natureza da ciência, e aspectos CTSA (Ciência, Tecnologia, Sociedade e Ambiente), e avaliar a aplicação desses textos junto a alunos de licenciatura em Química.

Para compreensão dos parâmetros norteadores desse trabalho, considera-se relevante delinear ideias de alguns teóricos que discutem e propõem esclarecimentos a respeito dessa temática.

\section{REFERENCIAL TEÓRICO}

\section{A Divulgação Científica em uma perspectiva Fleckiana}

Defende-se aqui a Divulgação Científica (DC) no âmbito da circulação intercoletiva de ideias. Dessa forma, o grupo dos que divulgam a Ciência constitui o ciclo esotérico, como observado na Figura 1:

Segundo Fleck (1986), o círculo esotérico, que congrega 


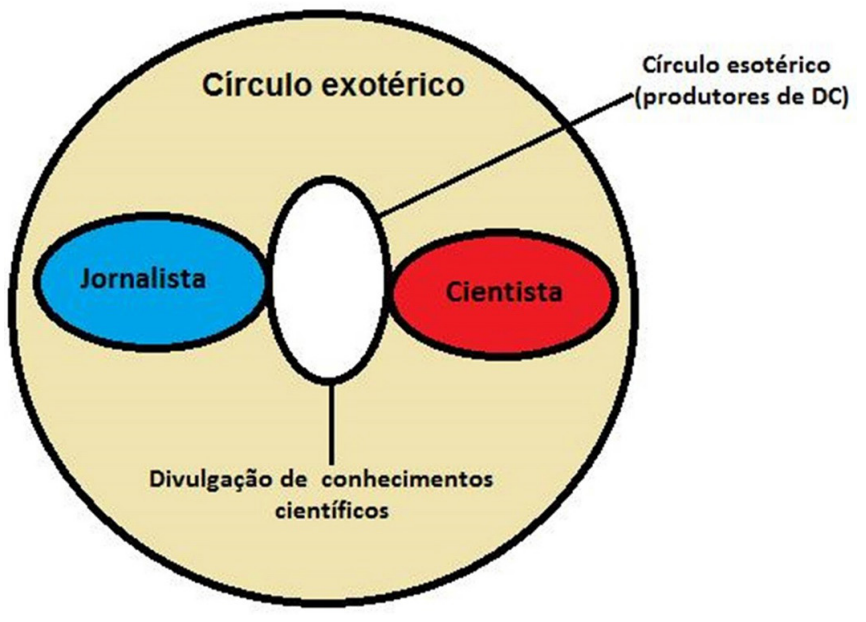

Figura 1: Relação entre os círculos esotérico e exotérico no contexto da Divulgação Científica. (Adaptado de NASCIMENTO, 2005, p.4).

os produtores de DC, sejam eles jornalistas ou cientistas, está envolto por um grande círculo exotérico composto pelo público de não especialistas, também conhecidos como leigos. Quando se trata de Divulgação Científica, os especialistas de uma determinada área transformam o conhecimento científico e o apresentam aos leigos. Por sua vez, o coletivo dos não especialistas (exotérico) pode avaliar, comparar, enfrentar e ressignificar esse conhecimento em seu contexto real e devolver para o coletivo esotérico. Essa troca dinâmica entre os grupos é denominada circulação intercoletiva de pensamentos. Fleck (1986) defende que, a partir do conhecimento especializado, proveniente do círculo esotérico, passa a existir o conhecimento popular, gerado no círculo exotérico. Esse epistemólogo salienta que, para acontecer a circulação intercoletiva de pensamento, faz-se necessário certo nível de convergência entre os dois círculos, para que os textos produzidos sejam minimamente compreendidos. Para tanto, o grupo esotérico deve adaptar cuidadosamente o conhecimento científico, transformando terminologias específicas, adequando as palavras ao público a que se destina o texto e lançando mão de "exposição artisticamente atrativa, viva e gráfica" (p.161).

Fleck (1986) também considerou a existência de circulação intracoletiva de ideias, por meio de revistas e manuais, reforçando as relações que existem dentro de um mesmo coletivo de pensamento. De modo geral, esse epistemólogo promoveu uma caracterização dos suportes materiais responsáveis pela veiculação de ideias científicas intra e intercoletivas a partir da distinção entre a ciência dos especialistas (saber especializado do círculo esotérico) e a ciência popular (saber popular do círculo exotérico) (NASCIMENTO, 2005).

\section{Divulgação Científica: funções e justificativas}

Utilizaremos o referencial de Bueno (2008) para a definição do termo divulgação científica. Segundo esse teórico, o processo de Divulgação Científica pode ser compreendido como uma adaptação da linguagem científica para a linguagem compreensível a uma vasta audiência. Assim,

A divulgação científica compreende a utilização de recursos, técnicas, processos e produtos (veículos ou canais) para a veiculação de informações científicas, tecnológicas ou associadas a inovações ao leigo. É importante perceber que divulgação científica pressupõe um processo de recodificação, isto é, a transposição de uma linguagem especializada para uma linguagem não especializada, com o objetivo primordial de tornar o conteúdo acessível a uma vasta audiência. (BUEN0, 2008, p.4).

A seguir, expomos as principais funções e justificativas defendidas na literatura relacionadas à veiculação de informações ao público, no sentido de ampliar a compreensão acerca da importância da DC para os diversos segmentos sociais.

Cini (1998) defende a necessidade de difundir o conhecimento científico para o público em geral, ressaltando a importância das pessoas adquirirem "um conhecimento sobre o que é Ciência, porque se faz Ciência, qual a relação entre o desenvolvimento científico e tecnológico e os problemas do seu cotidiano e da sociedade presente e futura" (p.9). Nessa perspectiva, destaca-se o papel social da divulgação científica, pois o indivíduo que tem acesso ao conhecimento básico sobre Ciência e como ela funciona pode entender melhor o contexto da sociedade em que está inserido e ter a capacidade de tomada de decisões, assumindo assim uma postura cidadã.

Por sua vez, Pérez, Molini (2004) e Estrada (2011) atribuem algumas funções básicas à DC, tais como: função informativa, educativa, social, cultural, econômica e político-ideológica. A partir dessas funções, defende-se neste artigo a ideia de que, visto a escola ter a responsabilidade social de formar cidadãos, a Divulgação Científica pode e deve permear o espaço escolar, assumindo as funções social e educativa que, nessa conjuntura, são indissociáveis.

Nesse contexto, Kreinz e colaboradores (2007) afirmam que, na perspectiva de José Reis, um dos papéis da Divulgação Científica está relacionado à educação formal: "a divulgação científica realiza duas funções que se completam: em primeiro lugar, a função de ensinar, suprindo ou ampliando a função da própria escola; em segundo lugar, a função de fomentar o ensino" (p.15).

Os argumentos de Carneiro (2009) também convergem para essa mesma reflexão. A autora entende que a Divulgação Científica pode contribuir para a melhoria do ensino de ciências no ambiente escolar formal, pois "a Divulgação Científica assume novo papel social: apoiar a educação científica ministrada na escola" (p.33). 
Além disso, a Divulgação Científica também tem sido vista por muitos autores como uma forma de contribuir para a desmistificação do cientificismo, ainda muito presente nos alunos da educação básica. No contexto atual, é perceptível o quanto os avanços tecnológicos têm sido marcantes nas diversas áreas do conhecimento. Esses avanços têm relação direta com a melhoria na qualidade de vida das populações. Por outro lado, muitas pessoas criaram uma falsa imagem de que a ciência é capaz de resolver todos os problemas do mundo e, muitas vezes, ignoram como a ciência funciona, seus obstáculos, seus possíveis riscos à sociedade e quais acertos e erros constituem o processo da ciência produzida.

Com isso, a intervenção da Divulgação Científica poderá contribuir para romper com a visão simplista sobre ciência. Nessa perspectiva, Kosminsky e Giordan (2002, p.11) “compreendem que as visões de mundo dos estudantes também devem ser influenciadas pelo pensamento científico e pelas expressões de sua cultura, cujos traços são parcialmente divulgados na mídia".

Com base nas reflexões acima, fica evidente a importância da Divulgação Científica para a sociedade, particularmente no ensino, favorecendo ao aluno uma intervenção crítica na realidade que o cerca. Considerando que a cidadania se refere à participação dos indivíduos na sociedade, torna-se claro que, para o cidadão efetivar a sua participação comunitária, é necessário que ele disponha de informações (SCHNETZLER e SANTOS, 2003). Portanto, acredita-se na DC como atividade educativa no âmbito escolar para promover a compreensão da ciência pelos alunos e possibilitar a utilização de seus conceitos em situações cotidianas.

\section{O Texto de Divulgação Científica no contexto da sala de aula}

Pensar nas formas de acesso ao conhecimento da ciência faz parte do processo de inserção da Divulgação Científica no ensino. Vários trabalhos relatados na literatura têm admitido diferentes formas de divulgar a ciência. Ela está presente, nas sociedades modernas, em diversos espaços sociais e em múltiplos meios de comunicação como jornais, televisão, cinema, museus, exposições, livros, revistas, cordéis e textos.

No universo das mais variadas formas de difundir o conhecimento científico e tecnológico, a presente pesquisa teve como foco os Textos de Divulgação Científica (TDC), com respaldo nos estudos de Ribeiro e Kawamura (2005). Segundo as autoras, a utilização de materiais de divulgação em ambientes de educação formal pode favorecer a introdução de novos sentidos de aprendizagem de ciências, proporcionando aos alunos a aproximação com diferentes linguagens e discursos. Além disso, compreendem os Textos de Divulgação Científica como possibilidades de trabalhar habilidades de leitura, de ter acesso às informações de ciência e tecnologia atualizadas, de proporcionar a formação de espírito crítico e reflexivo sobre o meio que o cerca e de promover o estímulo à participação dos alunos nas aulas.

Dialogando com as estudiosas citadas acima, a formação do espírito crítico volta-se para os olhares dos alunos quanto à produção do conhecimento científico e tecnológico e suas implicações no meio social, e para a formação da imagem da ciência como detentora não apenas de acertos, mas também de erros.

No que diz respeito ao acesso às informações atualizadas, vislumbra-se a transformação rápida e versátil da ciência em decorrência dos avanços da tecnologia, que os livros didáticos não conseguem acompanhar por serem produzidos para uma realidade escolar serial. Ainda que contenham textos contemporâneos, muitas vezes os livros didáticos não detêm informações atualizadas na esfera em que a realidade local do aluno se encontra inserida.

Contudo, apesar dos Textos de Divulgação Científica poderem ser usados como recursos didáticos, o professor deve ter a clareza quanto à intenção e a forma de utilização dos textos, pois, "além dos conteúdos, esses materiais apresentam linguagens, abordagens, discursos e estruturação diferentes daqueles que caracterizam os livros didáticos" (RIBEIRO; KAWAMURA 2005, p.12). Portanto, os Textos de Divulgação Científica na sala de aula devem ser introduzidos de maneira diferenciada dos conteúdos tradicionais. Isso implica em uma formação adequada por parte do professor, para que os textos não se transformem meramente em linhas em que os alunos leiam, memorizem e reproduzam em avaliações.

Nesse contexto, o contato com TDC durante o processo de formação docente é um ponto a ser considerado pelos cursos de licenciatura. Entretanto, uma revisão dos dez últimos anos de alguns periódicos relevantes na área do Ensino de Ciências indica a pouca utilização e produção desses textos nos cursos de nível superior. Os periódicos analisados foram: Investigação em Ensino de Ciências; Revista Brasileira de Pesquisa em Educação em Ciências; Ensaio-Pesquisa em Educação em Ciências; Ciência \& Educação; Revista Electrónica de Enseñanza de las Ciencias e Science Education.

No período compreendido entre 2005 e 2016, foram publicados um total de 2180 artigos nesses periódicos. Desse total, apenas $128(5,8 \%)$ têm como foco a Divulgação Científica. Dentre os artigos relacionados a essa temática, apenas doze abordam a produção e uso no âmbito do ensino superior, mais especificamente, nos cursos de Química (FERREIRA e QUEIROZ, 2012; QUADROS, SILVA e SILVA, 2011; STRACK et al., 2009; DIANOVSKY e WINK, 2011), Física (DIAS e ALMEIDA, 2010; ZANOTELLO e ALMEIDA, 2013) Biologia (NASCIMENTO e CASSIANI, 2009; PALCHA e OLIVEIRA, 2014; TERRA et al., 2014) e Ciências Naturais (NASCIMENTO e REZENDE, 2010).

Em relação à área da Química, foram encontrados três artigos com foco na leitura de TDC com posterior produção 
de textos ou questões; um artigo com o objetivo na produção de textos jornalísticos e um artigo com foco na percepção dos professores do curso de Química sobre a inserção da literatura de Divulgação Científica na prática docente. $\mathrm{Na}$ área da Física, foram encontrados dois artigos: um deles tinha como objetivo a leitura de um TDC e produção de questões a ele relacionadas, e o outro a análise discursiva de licenciandos, a partir da leitura de TDC. Já na área da Biologia, foram encontradas duas publicações com foco na leitura de TDC pelos licenciandos e suas reelaborações discursivas/produção textual, e um artigo que buscou identificar obstáculos epistemológicos em um TDC, a partir de sua utilização em uma turma de licenciandos. Já no curso de Ciências Naturais, foi encontrada apenas uma publicação, cujo objetivo foi o de analisar textos de divulgação escritos por alunos em formação inicial.

Além dos cursos acima mencionados, foi encontrada outra publicação sobre o uso de TDC no nível superior, mas no âmbito de um Projeto de Ensino Fundamental na Educação de Jovens e Adultos, no qual foram investigadas as práticas de leitura por licenciandos de diferentes cursos (RIBEIRO et al., 2012).

Estes dados evidenciam a pouca produção científica relativa à área da Divulgação Científica (apenas 5,8 \% do total de artigos publicados), e sua incipiente inserção no ensino superior.

\section{METODOLOGIA}

A pesquisa em questão está estruturada no referencial metodológico que enfatiza a abordagem qualitativa. Segundo Ludke e André (1986), a pesquisa qualitativa "supõe o contato direto e prolongado do pesquisador com o ambiente e a situação que está sendo investigada, via de regra, por meio do trabalho intensivo de campo". Além disso, tem como objetivo principal interpretar o fenômeno, norteada pela observação, pela compreensão, pela descrição e pelo significado.

No entanto, apesar de a pesquisa ter a predominância do caráter qualitativo, ressalta-se que, para quantificar opiniões a partir da coleta de dados, foi necessário utilizar dados estatísticos. Portanto, devido a essa complementaridade dos métodos quantitativos, a abordagem quantitativa também se insere no universo da presente pesquisa.

Participaram, como sujeitos da pesquisa, alunos ingressantes e alunos de semestre avançado do curso de Licenciatura em Química de uma universidade pública federal e de uma universidade pública estadual. A fim de preservar a identidade das universidades em que foi realizada a pesquisa, elas serão chamadas de Universidade A e Universidade $\mathrm{B}$, respectivamente. O número total de alunos da Universidade B foi 23, sendo 7 alunos de semestre inicial e 16 alunos de semestre avançado. O número total de alunos da Universidade A foi 42, sendo 23 alunos de semestre inicial e 19 alunos de semestre avançado.
No curso de Licenciatura em Química da Universidade A, os alunos ingressantes cursavam a disciplina Fundamentos de Química, ofertada no primeiro semestre, e os alunos de semestre avançado cursavam a disciplina Experimentação no Ensino de Química, ofertada no sétimo semestre. Já no curso de Licenciatura em Química da Universidade $\mathrm{B}$, os alunos ingressantes cursavam a disciplina Química Inorgânica, ofertada no segundo semestre do fluxograma do curso, e os alunos de semestre avançado cursavam a disciplina Estágio Supervisionado II, ofertada no sexto semestre.

A escolha das disciplinas foi feita de forma que participassem da pesquisa licenciandos com perfis diferentes: alunos recém-ingressos na universidade e alunos em final de curso. Os espaços foram cedidos pelos professores das universidades participantes nas disciplinas acima mencionadas.

Foram elaborados sete textos de divulgação científica como material de apoio ao ensino formal da Educação Básica. As temáticas escolhidas foram: o que é a Química e o que o químico faz; alimentos; metais; atmosfera; e água (os textos estão disponibilizados em PPGEC-UnB, 2012). A escolha dos temas foi baseada na relevância social, bem como na relação deles com o conhecimento químico e com aplicações no cotidiano. Ressalta-se que, para a pesquisa em questão, optou-se pela avaliação e análise profunda dos textos "O que é a Química e o que o químico faz" (texto 1) e "Alimentos" (texto 2), visto que todos estão escritos em um mesmo padrão que caracteriza um TDC.

Optamos por elaborar os textos pensando num contexto de Divulgação Científica para o ensino formal, visto que muitas vezes os TDC existentes não se enquadram nos critérios que adotamos como basilares para serem utilizados em sala de aula. O objetivo dessa elaboração foi o de contribuir para a produção de Textos de Divulgação Científica com finalidade essencialmente didática, e específica para o ensino formal. Como base para a construção desses textos, recorreu-se aos pesquisadores Ribeiro e Kawamura (2005). Em seus estudos, a caracterização do discurso da Divulgação Científica tem base nos três elementos essenciais: o tema, o estilo e a composição. Esses elementos serão detalhados mais à frente, haja vista que os aspectos que guiaram a construção dos textos foram os mesmos estabelecidos como critérios de avaliação pelos licenciandos.

A escrita dos textos foi conduzida pelas palestras de Divulgação Científica, realizadas no Laboratório de Pesquisas em Ensino de Química (LPEQ), através do projeto UnB-Tur. Esse projeto é desenvolvido pela Universidade de Brasília e um dos seus objetivos é favorecer a integração dos diferentes segmentos da comunidade acadêmica e da comunidade externa, viabilizando a difusão do conhecimento. A apresentação das palestras temáticas de Divulgação Científica tem a experimentação como eixo condutor. Adicionalmente, enfoca-se também a natureza e a História 
da Ciência. A escolha pelas palestras proferidas no LPEQ é justificada pelas contribuições efetivas que elas têm dado aos alunos e professores da educação básica. Uma pesquisa publicada nos anais do ENPEC demonstra que, nesse espaço, há uma significativa contribuição no que diz respeito à popularização do conhecimento científico, sobretudo dos conceitos relacionados com a Química, de modo que a metodologia de trabalho acreditada por esse laboratório aponta para um caminho de melhora no atual Ensino de Química (GOMES et al., 2011).

Os textos foram escritos em uma linguagem que se aproxima de uma interação dialógico-problematizadora para que, quando conduzidos na sala de aula, possam contemplar as vozes dos alunos, visto que "as interações discursivas são consideradas como constituintes do processo de construção de significados" (MORTIMER; SCOTT, 2002, p. 283).

As ferramentas para analisar a forma como os professores podem agir para guiar as interações que resultam em construção de significados em salas de aula encontram-se nos estudos de Mortimer e Scott (2002), os quais citamos ao longo da análise de dados.

A estratégia utilizada para investigar como os licenciandos avaliaram o material produzido e como eles percebem as potencialidades didáticas do uso de TDC no ensino foram os questionários semiestruturados, nos quais foi solicitado que alunos atribuíssem notas em uma escala de zero a três, correspondendo aos conceitos "não se aplica", "fraco", "médio" e "bom". Posteriormente, os alunos tiveram que identificar nos textos as linhas equivalentes a cada categoria estabelecida. Isso nos permitiu uma melhor compreensão de como os licenciandos percebem os elementos presentes nos textos.

Um ponto muito importante considerado nesta pesquisa diz respeito à prática docente: a partir das respostas analisadas, julgou-se a relevância dos Textos de Divulgação Científica como parte da formação do professor. Defendemos a ideia de que, no momento em que o licenciando avalia os textos produzidos, ele faz uma reflexão acerca dos critérios adotados como essenciais para um TDC com finalidades educacionais. Além disso, estamos possibilitando que tenha contato com um tipo de material didático diferente daqueles a que está acostumado em sua trajetória acadêmica. Essa proximidade, ainda que em um curto espaço de tempo, as reflexões inerentes à avaliação dos textos e as suas percepções em relação ao uso dos textos no ensino são consideradas por nós como uma iniciativa que pode contribuir para um aumento no interesse pelo uso de textos de DC no ensino.

Os resultados da pesquisa desenvolvida são apresentados em três vertentes, referentes à avaliação, pelos alunos, dos textos de acordo com três categorias: forma, conteúdo, e utilização de Textos de Divulgação Científica no Ensino.

\section{RESULTADOS E DISCUSSÃO}

\section{Avaliação referente à categoria forma}

Para que os alunos pudessem avaliar os textos quanto à forma, criamos subitens objetivando uma avaliação mais detalhada. Tais subitens, também utilizados como parâmetros para a construção dos textos, foram guiados à luz de Ribeiro e Kawamura (2005) e agrupados em oito categorias: adequação dos recursos visuais e textuais; relevância social da temática; uso de termos científicos seguidos de uma explicação; percepção de conteúdos de Química; abordagem do tema em uma sequência lógica; diálogo entre o leitor e o autor; e esclarecimento de fenômenos curiosos do dia a dia.

\section{Recursos visuais e textuais}

A categoria de recursos visuais e textuais, proposta por Ribeiro e Kawamura (2005), diz respeito à distribuição espacial das informações. Para as autoras, essa distribuição opera no sentido de atrair o leitor para o texto. Elas consideram, como exemplos de recursos visuais, as ilustrações e fotografias e, de recursos textuais, os boxes, as notas de margens, as pequenas inserções de textos no texto principal, etc.

Nos textos produzidos, buscamos explorar mais o uso de tabelas, ilustrações e boxes articulados ao conteúdo explorado. Compreende-se aqui que os recursos visuais explorados em textos são elementos que facilitam, ao leitor, a compreensão do que está sendo dito. No entanto, entendemos ser necessária a intervenção do professor no tocante ao uso de imagens, pois elas podem proporcionar ao leitor diferentes interpretações. Como os textos de Divulgação Científica foram escritos na perspectiva de torná-los recursos de apoio didático ao professor, entendemos ser adequado o uso de imagens, não comprometendo os seus significados. Isso porque, mesmo que as figuras apresentem diferentes sentidos, o professor, na função de orientador, pode promover discussões e momentos de interação entre professor/aluno e aluno/aluno. Os resultados para a categoria em questão podem ser melhores visualizados no Quadro 1.

De acordo o Quadro 1, observa-se que, para o texto 1, intitulado "O que é a Química e o que o químico faz", cinco alunos de semestre inicial da Universidade B avaliaram os recursos visuais como "médio" e "não se aplica", totalizando $71,4 \%$, o que indica que apenas $28,6 \%$ atribuíram o conceito de "bom". Já entre os respondentes de semestre avançado, 7 avaliaram o texto como "médio" ou "fraco", totalizando $50 \%$. Para o texto 2, intitulado "Alimentos", seis alunos de semestre inicial avaliaram esse subitem como "médio" ou "fraco", totalizando $85,7 \%$, o que indica que apenas $14,3 \%$ consideram os recursos visuais bons. Dos alunos 
Quadro 1: Avaliação dos licenciandos em relação à categoria recursos visuais e textuais. (Texto 1: O que é a Química e o que um químico faz? e texto 2: Qual a relação da Química com os alimentos)

\begin{tabular}{|ccccccc|}
\hline INSTITUIÇÃO & $\begin{array}{c}\text { PERFIL DO } \\
\text { LICENCIANDO }\end{array}$ & TEXTO & AVALIAÇÃO & $\begin{array}{c}\text { \% DE } \\
\text { ALUNOS }\end{array}$ & CONCEITO \\
& ALUNOS & Bom & 28,6 \\
Universidade B & Semestre inicial & 1 & Médio/Não se aplica & 71,4 & 50 & Bom \\
Universidade B & Semestre avançado & 1 & Médio/Fraco & 50 & Bom & 14,3 \\
Universidade B & Semestre inicial & 2 & Médio/Fraco & 85,7 & Bom & 6,3 \\
Universidade B & Semestre avançado & 2 & Médio/fraco & 93,7 & Bom & 43,7 \\
Universidade A & Semestre inicial & 1 & Médio & 47,8 & Bom \\
Universidade A & Semestre inicial & 2 & Médio & 42 & 36,8 \\
\hline
\end{tabular}

de semestre avançado, 15 deles atribuíram os conceitos "fraco" ou "médio", totalizando 93,7\%, o que indica que apenas $6,3 \%$ consideram bons os recursos visuais do texto. Já os resultados dos alunos da Universidade A mostram que $47,8 \%$ dos ingressantes atribuíram conceito "médio" para os recursos visuais e textuais do texto 1 , e que $42 \%$ dos alunos de semestre avançado também consideram "médio" estes recursos no texto 2 .

Observamos que um grande percentual de alunos atribuiu os conceitos "fraco" e "médio" ao analisarem os recursos visuais, sendo inclusive encontrados comentários relativos à qualidade das imagens nos textos, como destacado por uma aluna:

"apesar das figuras estarem conectadas com o que o texto está dizendo, elas estão ruins de ser visualizadas. Sugiro que aumente o tamanho e deixe o texto mais colorido".

Por um lado, esses resultados já eram esperados, pois os textos foram aplicados antes mesmo da edição final. Por outro, sabemos que não é uma prática comum o uso e a discussão sobre textos de Divulgação Científica como material didático nas disciplinas dos cursos de Licenciatura dos estudantes participantes dessa avaliação. Dessa forma, ao avaliarem os recursos visuais, os alunos o fizeram sem a compreensão da relevância das imagens em TDC. Entretanto, o resultado da avaliação permitiu-nos ampliar a compreensão sobre o papel das figuras e das iconografias nos textos de DC, e nos possibilitou buscar um diálogo entre o verbal e o visual, tornando mais clara a comunicação de ideias na versão final dos textos. Segundo Souza e Giering
(2010), os infográficos podem ser também entendidos como um tipo de textualização que funde palavra e imagem, visando sintetizar e complementar as informações verbais e escritas. Os Textos de Divulgação Científica fazem uso da infografias, visando a apropriação, pelos leitores, de conceitos e ideias atreladas ao conhecimento científico (PIMENTA e GOUVÊA, 2009). Na versão final dos textos, buscou-se um maior investimento na qualidade das imagens, como pode ser observado no endereço eletrônico do Programa de Pós-Graduação em Ensino de Química da Universidade de Brasília (PPGEC-UnB, s/d).

\section{Temática de relevância social}

A escolha de temas para os textos foi realizada à luz de algumas concepções e questionamentos freireanos. Por que não estabelecer uma necessária "intimidade" entre os saberes curriculares fundamentais dos alunos e a experiência social que eles têm como indivíduos?

Nessa perspectiva, na escolha das temáticas, tivemos uma preocupação em abordar temas de interesse social e contemplar aspectos relativos à cidadania que possam ser explorados em sala de aula. A intencionalidade dos nossos temas foi de articular o saber científico em um contexto de vida do leitor. Dessa forma, não o dissociamos do contexto social no qual está inserido. Além disso, acreditamos que uma boa escolha do tema pode tornar a leitura mais prazerosa, curiosa e de interesse dos alunos-leitores. Os resultados para essa categoria estão expressos no Quadro 2.

Quadro 2: Avaliação dos licenciandos em- relação à categoria "Temática de relevância social"

\begin{tabular}{|ccccc|}
\hline INSTITUIÇÃO & PERFIL DO LICENCIANDO & TEXTO & AVALIAÇÃO & PORCENTAGEM \\
\hline Universidade B & Semestre inicial & 1 & Bom & Bom \\
Universidade B & Semestre avançado & 1 & Bom & $71,4 \%$ \\
Universidade A & Semestre inicial & 1 & Bom & 86,9 \\
Universidade A & Semestre final & 2 & Bom & 84,2 \\
Universidade B & Semestre inicial & 2 & Bom & 81,2 \\
Universidade B & Semestre final & 2 & 100 \\
\hline
\end{tabular}


Os resultados mostram que $100 \%$ dos alunos de semestre inicial da Universidade B avaliaram o texto 1 com nota máxima, que corresponde ao conceito "bom", e que 71,4\% dos alunos de semestre avançado atribuíram conceito "bom" para esse mesmo texto. A tendência dos alunos gostarem das temáticas dos textos foi a mesma na Universidade A, em que $86,9 \%$ dos alunos ingressantes avaliaram como "bom" o texto 1 e $84,2 \%$ dos alunos mais adiantados no curso avaliaram como "bom" o texto 2 . Os resultados também foram satisfatórios para o texto 2 que, na avaliação dos estudantes da Universidade B, obteve porcentagem do conceito bom acima de $80 \%$.

$\mathrm{Na}$ avaliação de um dos alunos, o tema referente ao texto 1 lhe pareceu relevante porque:

"Esclarece o papel do Químico, abordou questões como sustentabilidade e preservação, que são de extrema importância nesses últimos tempos".

Destacamos algumas passagens dos textos que remetem à temática escolhida como instrumento de relevância social, validando assim os resultados aqui apresentados:

"Portanto, o profissional da Química produz essa substância no laboratório, destacando assim, a importância da sua atuação na nossa sociedade".

"Atualmente, a canela, além de ser usada na alimentação, é muito utilizada na produção de aromas e de medicamentos"

Na perspectiva bakhtiniana, "o tema é um sistema de signos dinâmico e complexo, que procura adaptar-se adequadamente às condições de um dado momento da evolução" (BAKHTIN, 2006, p.129). Aproximando essa definição da prática de Divulgação Científica, já que ela é constituída pelo gênero de discurso, o tema deve estar associado a assuntos de relevância social da época em que está sendo escrito. $\mathrm{O}$ comentário acima do aluno é um indicativo de que o tema que escolhemos para desenvolver o texto converge com a proposta de Bakhtin no que tange ao conteúdo temático como um gênero discursivo.

Esses resultados evidenciam que as abordagens dos temas dos TDC escolhidos foram bastante pertinentes, sendo avaliadas de forma satisfatória. Essa avaliação corroborou nossa intencionalidade de elaborar textos cujas temáticas possam propiciar leituras críticas das relações entre ciência, tecnologia e sociedade em sala de aula.

\section{Termos científicos seguidos de uma explicação e conteúdo de Química}

É certo que, no Texto de Divulgação Científica, se deve evitar o uso de uma linguagem esotérica, uma vez que a análise muito exaustiva desses termos tornaria a leitura cansativa, fugindo da perspectiva de um TDC. No entanto, sabemos que em alguns casos é impossível evitar a utilização de termos científicos. Nos textos produzidos, quando foi necessário recorrer ao uso desses termos, priorizou-se fazer passagens explicativas. Por exemplo, no texto 1, para explicar o impacto do uso inadequado dos detergentes, considerou-se necessário falar sobre tensão superficial, como descrito a seguir:

O detergente reduz a tensão superficial da água, formando uma espuma branca na superfície dos rios e impedindo assim a oxigenação dos ambientes aquáticos.

Em seguida, buscamos fazer uma breve explicação acessível desse conceito científico:

A tensão superficial é uma camada na superfície da água que se comporta como uma membrana elástica, devido às moléculas de água, que interagem entre si.

Sobre isso, Zamboni (2001) afirma que "a preocupação com a explicação de termos científicos, embora promova uma quebra na sequência de exposição das informações novas, também estimula o leitor a dar continuidade à leitura".

Em relação à abordagem de conteúdos de Química, buscamos, de forma didática e não conteudista, contemplar alguns aspectos científicos dessa ciência, visto que os Textos de Divulgação Científica, quando são escritos no âmbito da educação formal, configuram-se como uma estratégia de levar o conhecimento acadêmico para a sala de aula. Dessa forma, todos os textos buscaram abordagens de conteúdo acadêmico, de fato, articulados ao contexto social dos alunos.

De modo geral, os resultados mostraram que mais de $70 \%$ do universo de alunos conseguiu vislumbrar que nos textos foram contemplados conteúdos de Química, e que foram utilizadas estratégias discursivas, como exemplificações e explicações ao longo da escrita dos textos, a fim de tornar claros os termos que julgamos não ser de uma linguagem familiar ou cotidiana.

Satisfatoriamente, os resultados evidenciam que os textos que escrevemos contemplaram ambas as categorias. Pretendemos que o uso desses textos de divulgação, na constituição do discurso científico escolar e sua inserção nas aulas de ciências, seja facilitador da incorporação de alguns conceitos científicos.

\section{Abordagem em uma sequência lógica}

Ao longo da escrita dos textos, os argumentos foram conduzidos por intermédio de evidências científicas que os sustentam, na intenção de torná-los lógicos. Além disso, procurou-se causar uma percepção ao leitor de um texto coerente, de modo que a leitura não esteja limitada à decifração 
de palavras e frases, mas que possibilite a compreensão e reflexão do texto como um todo.

Parece que conseguimos alcançar esse objetivo, como pode ser observado no Quadro 3.

O número de estudantes da Universidade B que avaliaram a sequência lógica do texto 1 com o conceito "bom" correspondeu a 57\% (para estudantes de semestre inicial) e $71 \%$ (para estudantes de semestre avançado). Para o texto 2 , o percentual de alunos que atribuiu este mesmo conceito foi de $71 \%$ e $62,5 \%$ nos respectivos semestres. Esses resultados não variaram muito para os alunos da Universidade A, pois o conceito "bom" foi atribuído por $83 \%$ dos alunos ingressantes para o texto 1 e por $58 \%$ dos alunos de semestre avançado para o texto 2 .

\section{Diálogo entre o leitor e o autor}

A linguagem dialógica foi outro quesito que guiou a escrita dos textos, pois concordamos com Freire quando diz que "ensinar exige disponibilidade para o diálogo" (FREIRE, 2007, p.135). O objetivo para essa categoria é que o uso do material produzido possa contemplar esse diálogo, ou seja, que a leitura perpasse por diferentes vozes - tanto pela voz do autor quanto pela voz do professor, estudante ou de quem mais se interesse por ele. Para atender a essa prerrogativa, buscou-se a utilização de aspectos problematizadores (elemento chave no ensino progressista de Paulo Freire) que permitem criar possibilidades de discussão, como evidenciado nas passagens dos textos destacadas a seguir:

A glicose é produto do metabolismo da substância sacarose (açúcar). Você já parou para pensar o que causa o acúmulo de glicose no sangue?

O olhar do químico sobre a matéria é o que a diferencia das outras ciências. Do ponto de vista da Química, a matéria se apresenta na natureza na forma de materiais. Mas o que podemos definir como materiais?

Pretendemos, por exemplo, com os questionamentos acima, que os discursos dos alunos, do professor e do texto se entrecruzem e que promovam a reflexão, a articulação de ideias e a (re)construção de significados pelos alunos sobre o tema e conceitos explorados ao longo do texto. Esse tipo de discurso é considerado por Mortimer e Scott (2002) como uma abordagem comunicativa interativa/dialógica.

Além disso, pretende-se que todas as passagens das abordagens comunicativas contemplem, também, o que os autores acima chamam de abordagem comunicativa interativa de autoridade, ou seja, abordagem na qual apenas uma "voz" é ouvida e não há inter-animação de ideias. No texto sobre alimentos, iniciamos questionando ao leitor de que forma a Química se faz presente no nosso dia a dia. Essa pergunta inicial foi se entrelaçando com as abordagens e conceitos presentes no texto, possibilitando discussões a esse respeito, sendo possível valorizar a voz dos estudantes. Contudo, o texto é finalizado com uma abordagem comunicativa de autoridade:

Podemos finalizar afirmando que a Química é a ciência que estuda substâncias e que elas estão presentes nos diferentes tipos de alimentos.

Os resultados para essa categoria foram satisfatórios, podendo ser visualizados no Quadro 4.

Observa-se que, na avaliação dos alunos da Universidade B para o texto 1 , o total de alunos de semestre inicial que atribuíram conceito "bom" foi de $57 \%$, e o total de alunos do semestre avançado que atribuiu esse conceito foi de $85,7 \%$. Para o texto 2 , o total de alunos que atribuíram conceito "bom" representou $85,7 \%$ e $68,7 \%$ nos respectivos semestres. Da mesma forma, o conceito "bom" para os textos 1 e 2 foi atribuído por mais da metade dos alunos da Universidade A.

\section{Permite esclarecer fenômenos do dia a dia}

Entendendo que a Divulgação Científica, no âmbito do espaço escolar, pode atuar como uma interface entre o conhecimento científico, escolar e cotidiano, os textos foram produzidos na pretensão de abarcar essa interface, fornecendo esclarecimentos sobre alguns fenômenos do dia a dia desse público. No texto 2 , por exemplo, foram feitos alguns questionamentos ao leitor, como, por exemplo:

Quadro 3: Avaliação dos licenciandos em relação à categoria "sequência lógica"

\begin{tabular}{|ccccc|}
\hline INSTITUIÇÃO & PERFIL DO LICENCIANDO & TEXTO & AVALIAÇÃO & PORCENTAGEM \\
\hline Universidade B & Semestre inicial & 1 & Bom & $57 \%$ \\
Universidade B & Semestre avançado & 1 & Bom & $71 \%$ \\
Universidade B & Semestre inicial & 2 & Bom & $71 \%$ \\
Universidade B & Semestre final & 2 & bom & $62,5 \%$ \\
Universidade A & Semestre inicial & 1 & Bom & $83 \%$ \\
Universidade A & Semestre final & 2 & Bom & $58 \%$ \\
\hline
\end{tabular}


Quadro 4: Avaliação dos licenciandos em relação à categoria "diálogo entre o leitor e o autor"

\begin{tabular}{|ccccc|}
\hline INSTITUIÇÃO & PERFIL DO LICENCIANDO & TEXTO & AVALIAÇÃO & PORCENTAGEM \\
\hline Universidade B & Semestre inicial & 1 & Bom & $57 \%$ \\
Universidade B & Semestre avançado & 1 & Bom & 85,7 \\
Universidade B & Semestre inicial & 2 & Bom & 85,7 \\
Universidade B & Semestre final & 2 & Bom & 68,7 \\
Universidade A & Semestre inicial & 1 & Bom & $58 \%$ \\
Universidade A & Semestre final & 2 & Bom & $60 \%$ \\
\hline
\end{tabular}

Quando você degusta uma bala de canela, é possível identificar dois sabores: o sabor doce e o sabor de canela. Mas afinal, como esses sabores foram parar na bala?

Ao longo do texto, o questionamento foi respondido utilizando fenômenos, explicações e figuras.

Nesse quesito, os resultados também foram satisfatórios, como pode ser observado no Quadro 5.

As falas a seguir são indicativas de que o material produzido contemplou bem essa categoria:

"Além de explicar algumas funções do químico, o texto apresentou vários fatos curiosos que são explicados de maneira simples com alguns conceitos da ciência".

"Ele mostra coisas que usamos no dia-a-dia e que não sabemos."

Ressalta-se que a categoria em questão está inclusa apenas no questionário para os alunos de semestre inicial, visto que o quesito "O uso dos textos de Divulgação Científica", que se encontra no questionário elaborado para os alunos de semestre avançado, já contempla essa categoria.

\section{Avaliação referente à categoria forma}

A referência basilar para a criação das categorias foi o instrumento de análise proposto por Ribeiro e Kawamura (2005). No entanto, ressaltamos que foram feitas algumas adaptações desse instrumento, na intenção de complementar e ampliar os elementos que caracterizam um TDC. Adicionalmente, a categoria "aspectos da História da Ciência" foi incluída com base nos estudos de Pereira e Silva (2009). Sendo assim, as categorias estabelecidas, tanto para avaliação quanto para a elaboração dos textos, foram: aspectos da relação fenômeno-teoria, aspectos da natureza do conhecimento científico, aspectos da história da ciência, aspectos CTSA, aspectos das relações éticas de consumo e cidadania, aspectos interdisciplinares e aspectos problematizares, abrindo possibilidades de discussão.

\section{Aspectos da relação fenômeno-teoria}

O uso de fenômenos reais foi um dos eixos condutores na produção dos textos e aconteceu à luz das propostas de experimentação no Ensino de Ciências (SILVA, MACHADO e TUNES, 2010). Para esses autores, a experimentação no ensino pode ser entendida como "uma atividade que permite a articulação entre fenômenos e teorias. Dessa forma, o aprender Ciências deve ser sempre uma relação constante entre o fazer e o pensar".

Curiosamente, apesar dos resultados terem sido satisfatórios, já que mais de 50\% dos licenciandos participantes atribuíram conceito "bom", esses mesmos alunos identificaram, nos textos, aspectos da relação fenômeno-teoria de forma equivocada:

[...] a diferença nas densidades pode ser atribuída às massas distintas dos líquidos.

A tensão superficial é uma camada na superfície da água que se comporta como uma membrana elástica, devido às moléculas de água que interagem entre si.

Os trechos acima foram os mais citados pelos alunos, tanto de semestres iniciais quanto de semestres avançados, quando solicitamos que citassem alguma passagem no texto que contemplasse a categoria fenômeno-teoria. As respostas dos alunos foram consideradas equivocadas, pois eles representaram apenas a teoria, esquecendo-se da

Quadro 5: Avaliação dos licenciandos em relação à categoria "fenômenos do dia a dia"

\begin{tabular}{|ccccc|}
\hline INSTITUIÇÃO & PERFIL DO LICENCIANDO & TEXTO & AVALIAÇÃO & PORCENTAGEM \\
\hline Universidade B & Semestre incial & 1 & Bom & $57 \%$ \\
Universidade B & Semestre inicial & 2 & Bom & $100 \%$ \\
Universidade A & Semestre inicial & 1 & Bom & $73 \%$ \\
\hline
\end{tabular}


parte experimental. Por exemplo, esperava-se que os alunos explicitassem o fenômeno de flutuação e o de submersão das latas de refrigerante e, em seguida, explicitassem a interpretação microscópica. No entanto, como observado no trecho acima, apenas a teoria foi explicitada, indicando assim a dissociabilidade da relação fenômeno-teoria representada pelos alunos.

Com esses resultados, podemos inferir que os saberes práticos e teóricos ainda estão dissociados nesses alunos. A hipótese aqui prevista para justificar a ausência da inter-relação entre esses saberes está associada à natureza pedagógica da experimentação para muitos professores, o que se reflete em suas salas de aulas. As atividades experimentais marcantes nos cursos de licenciatura em Química ainda caracterizam um ensino simplista, em que se nota uma visão empirista do observar, pela qual a simples observação de um fenômeno conduz a uma teorização sobre ele. Normalmente, os alunos têm uma aula teórica e depois vão para o laboratório, e o discurso do professor que prevalece na aula experimental é a comprovação do que foi dito na aula teórica. Assim, os alunos são impregnados, ao longo de sua formação, com a ideia de que o papel da experimentação é o de comprovar as teorias já estabelecidas nas ciências.

Os resultados para essa categoria apontam a necessidade de propostas que busquem romper com visões simplistas que pontuam as atividades experimentais como validação e comprovação da teoria, ou seja, a experimentação como um método verificacionista. Essas propostas podem, por exemplo, ser trabalhadas nas disciplinas pedagógicas do curso de licenciatura e aplicadas nas turmas de estágio supervisionado. Silva, Machado e Tunes (2010) sinalizam como uma alternativa possível às aulas experimentais que contemplem a relação teoria-fenômeno a inserção de atividades demonstrativas-investigativas.

No âmbito da Divulgação Científica no espaço escolar, espera-se que a utilização dos TDC produzidos possa contribuir também para a superação da visão dogmática de ciência segundo a qual a teoria explica o fenômeno, já que a experimentação foi um dos eixos norteadores para a produção desse material.

\section{Aspectos da natureza do conhecimento cientifico (NCC)}

Para essa categoria, o percentual de alunos que atribuíram conceito "bom" foi menor que $50 \%$ e, para muitos deles, os aspectos da NCC não se aplicam nos textos. Isso é um indicativo de que tanto os alunos de semestres iniciais quanto os de semestres avançados não têm a percepção do que seja NCC. Tal afirmação sobre a ausência do entendimento e da percepção da NCC nos alunos foi respaldada pelo grande número de respostas deixadas em branco quando pedimos para que identificassem nos textos as linhas que correspondem a aspectos da Ciência e a sua natureza. Foram muito frequentes as seguintes respostas:

"Não sei o que é isso" / "Não consigo identificar" / "Não aprendi sobre isso"

Esses resultados fornecem importantes subsídios para a discussão a respeito das concepções dos alunos de Ensino Médio e de Ensino Superior sobre a natureza da Ciência. Não nos surpreendemos com os resultados das avaliações dos alunos recém-ingressantes, pois, sendo alunos que acabaram de sair do Ensino Médio, as lacunas de uma formação desejável em relação às percepções da NCC são refletidas quando se chega à universidade. Segundo Soares e Xavier (2008), alunos ingressantes do curso de Química, geralmente, têm uma má formação em termos de Ensino Médio, seja no que se refere à própria Química, seja no que se refere à sua visão de ciências.

As constatações dessas lacunas são reforçadas nos estudos de Silva (2010). Resultados de sua pesquisa apontam para as "discrepâncias entre as visões de natureza da ciência consideradas como mais corretas e consensuais pela literatura da área e as apresentadas pelos estudantes do Ensino Médio".

Essa realidade dos alunos do Ensino Médio, possivelmente, decorre da ausência de uma formação epistemológica adequada de seus professores. No âmbito das preocupações atuais, na área de ensino de Ciências, espera-se que os cursos de licenciatura possam contribuir para fornecer aos alunos em formação uma visão mais adequada da natureza da ciência e das discussões epistemológicas pertinentes. Os atuais licenciandos, que se preparam para atuar como professores no Ensino Médio, precisam ter um entendimento significativo sobre o que é natureza da Ciência, quais são os seus potenciais e as suas limitações.

De modo geral, esses resultados vêm corroborar os dados de outras pesquisas (HARRES, 1999; LIMA e NÚÑEZ, 2011; SCHEID et al., 2009) sobre concepção de natureza da ciência e a educação científica na formação inicial, pois as análises das avaliações nos mostram que a visão dos alunos ingressantes e formandos não são diferentes. Em outras palavras, os licenciandos pesquisados apresentam dificuldades de compreensão em relação à natureza da ciência e às suas características. Esses estudantes afirmam não saber o que é a natureza da ciência, prejudicando a avaliação dos textos para esse quesito. Por outro lado, sinalizamos que o atual modelo de formação inicial precisa ainda ser repensado, de modo a estabelecer reflexões sobre como e por que utilizar abordagens sobre NCC. Sendo assim, espera-se que os textos produzidos, idealizados para utilização em sala de aula, possam favorecer um ensino em consonância com as concepções racionalistas e construtivistas a respeito da natureza do conhecimento científico. 


\section{Aspectos da história da ciência (HC)}

O percentual de alunos de semestre inicial, tanto da Universidade B quanto da Universidade A, que atribuíram conceito "bom" foi menor que 50\%. Além disso, um número significativo desses alunos atribuiu nota zero a essa categoria, correspondendo ao conceito "não se aplica". Além disso, quando foi pedido para que identificassem no texto aspectos da $\mathrm{HC}$, o trecho que prevaleceu com frequência em quase todas as respostas foi uma passagem que relatava data e nomes de cientistas:

Neste ano de 2011 comemora-se o Ano Internacional da Química, em homenagem ao $100^{\circ}$ aniversário do Prêmio Nobel de Marie Curie, pela sua descoberta dos elementos radioativos rádio e polônio e ao $100^{\circ}$ aniversário da Fundação da Associação Internacional das Sociedades Químicas.

Isso é um indicativo de que eles não conseguiram visualizar as passagens que retrataram aspectos da História da Ciência nos textos. Pressupõe-se que esses alunos não apresentam clareza a respeito desse tipo de abordagem. A hipótese aqui é que, sendo recentes egressos do Ensino Médio, eles chegam à universidade sem uma percepção a respeito dessa temática.

Essa hipótese é respaldada pelos estudos de Filho et al. (2005, p.1). Os autores apontam, como resultado de pesquisa sobre a abordagem da História da Química no Ensino Médio, que "os relatos dos livros didáticos analisados são, muitas vezes, lembretes de nomes de famosos cientistas e a época de experimentos, não se caracterizando como uma abordagem histórica. Além disso, nas abordagens não ocorrem contextualizações dos fatos, sendo estes muitas vezes distribuídos pelo texto sem uma ligação histórica".

No que concerne à avaliação pelos alunos de semestres avançados, observou-se que o percentual desses alunos que atribuíram a nota máxima para a categoria em questão variou entre $60 \%$ e $68 \%$. Isso é um indicativo de que os mesmos conseguiram visualizar aspectos da História da Ciência nos textos. Ao se pedir que identificassem, no texto 1 , aspectos da $\mathrm{HC}$, prevaleceu o seguinte trecho:

Essa doença no final da Idade Média se tornou epidêmica no norte da Europa. A incidência foi diminuída a partir do século XVII, com a introdução da batata como fonte de vitamina $\mathrm{C}$ na dieta alimentar europeia.

Para o texto 2, um dos trechos citados com frequência pelos estudantes foi:

Na Antiguidade, o cravo-da-índia, a pimenta-do-reino, o gengibre, bem como a canela, eram consideradas especiarias de grande valor comercial. Na época das grandes navegações, eram utilizadas como moedas de troca, dotes, heranças, reserva de capital, divisas de um reino, pagavam serviços, impostos, dívidas, acordos e obrigações religiosas.

Uma possível justificativa para a discrepância entre a avaliação dos alunos de semestres iniciais e de semestres avançados está relacionada à inserção da História da Química nos cursos de Licenciatura em Química da Universidade A e da Universidade B. Acredita-se que os alunos que já estão adiantados no curso, e já passaram por disciplinas de História da Química, possuam uma percepção sobre HC diferenciada dos alunos que são recém-ingressantes, o que se refletiu nos resultados dessa categoria.

Dessa forma, os resultados apresentados indicam que as reflexões, nos cursos de licenciatura, a respeito da inserção da História da Ciência no currículo podem despertar a percepção desses futuros docentes sobre as abordagens sócio-históricas no contexto da Química.

O encaminhamento dessas questões passa por uma perspectiva positiva no uso dos textos da Ciência e sua divulgação. A utilização de TDC nos parece ser um dos caminhos possíveis para que a abordagem de aspectos históricos seja ampliada nos cursos de formação inicial, e por isso, buscou-se contemplá-los ao longo dos textos. Assim, espera-se que os textos produzidos sejam utilizados de forma a criar oportunidades para se discutir com os alunos a inserção e o papel da História da Ciência para uma visão mais ampla e reflexiva da Ciência.

\section{Aspectos CTSA e aspectos das relações éticas de consumo e cidadania}

Na medida que um dos objetivos do Ensino de Ciências está voltado para a cidadania, pautamos a escrita dos textos, também, como uma proposta para favorecer o Ensino de Química com uma abordagem das relações entre Ciência, Tecnologia Sociedade e Ambiente. A perspectiva é torná-la uma possível forma de desenvolver, junto aos alunos, o pensamento crítico sobre essas relações, bem como uma postura ética de consumo e cidadania.

Os resultados das avaliações, tanto para o texto 1 , quanto para o texto 2, mostraram que o percentual de alunos de semestre inicial e avançado das duas universidades que avaliaram com o conceito "bom" as duas categorias em questão foi maior que $60 \%$. Esses resultados são evidências de que conseguimos contemplar o conhecimento científico articulado com alguns aspectos sociais, tecnológicos e ambientais. Outras evidências que nos permitem tecer considerações nesse sentido foram os trechos extraídos pelos alunos como exemplos da expressão desses aspectos nos textos: 
A Química é uma ciência de extrema importância para a sustentabilidade e as atividades do químico podem proporcionar uma melhor qualidade de vida para a humanidade, como por exemplo, a síntese de medicamentos para a cura de doenças, a produção de energia, a conservação dos alimentos, etc.

Utilizar apenas a quantidade necessária de detergente ajuda na diminuição desses impactos, por isso, use e abuse dessa informação para agir de forma mais consciente e ajudar na preservação de nosso planeta.

Sabemos que nem todos podem degustar uma bala de canela ou qualquer alimento adocicado com açúcar, devido à doença diabetes.

Por isso, não devemos abusar de doces, salgadinhos, bebidas alcoólicas e precisamos praticar atividades físicas regularmente.

Por fim, quero usar este momento para sensibilizar a você, caro leitor, de que para nos mantermos vivos é preciso, primeiramente, mantermos a natureza viva. Por isso, adote o consumo sustentável e contribua na preservação do meio ambiente. Ademais, diria tal qual João Bosco da Silva: "A responsabilidade social e a preservação ambiental significam um compromisso com a vida."

Contemplando a abordagem de aspectos Ciência, Tecnologia, Sociedade e Ambiente, de modo a desenvolver valores e atitudes comprometidos com a cidadania, pretende-se que o material produzido, no âmbito da Divulgação Científica em espaços formais, possa contribuir na formação dos alunos como cidadãos atuantes na sociedade, capazes de perceber, questionar e se posicionar frente às situações cotidianas.

Ressalta-se que, para a proposta da utilização dos textos terem resultados positivos no que tange à sala de aula do Ensino Médio, é imprescindível, e acima de tudo inerente ao Ensino de Ciências voltado para dimensões CTSA, que os professores se conscientizem de que o papel do educador é, também, o de construir e expressar essas relações no processo de ensino. Nesse sentido, os espaços de formação inicial e continuada de professores devem favorecer questionamentos que envolvam discussões sobre esse tema.

\section{Aspectos interdisciplinares}

Atualmente, as propostas de práticas interdisciplinares para o Ensino de Ciências mais citadas na literatura são a construção de unidades didáticas, e a execução de projetos e oficinas temáticas.
Tendo em vista o potencial didático de Textos de Divulgação Científica, já discutido em linhas anteriores, a nossa proposta de prática interdisciplinar é a produção de textos dessa natureza para uso na sala de aula. Assim, escrevemos os textos de modo que as temáticas escolhidas fossem compreendidas como um elo entre as diferentes áreas, opondo-se ao conhecimento fragmentado trabalhado nas escolas.

Os resultados das avaliações, tanto para o texto 1 quanto para o texto 2, mostraram que o percentual de alunos de semestre inicial das duas universidades que avaliaram com o conceito "bom" as duas categorias em questão foi, em média, de $40 \%$. Os trechos mais frequentes que os alunos de semestres iniciais identificaram como sendo de abordagem interdisciplinar foram:

Muitos dizem que a Química é a ciência que estuda a matéria. No entanto, essa é uma afirmação muito geral, pois a Biologia, a Física e a Geologia também estudam a matéria. (texto 1 )

Você já deve ter escutado falar da Química da saúde, Química do Meio Ambiente, Química dos materiais, Química dos sentidos, Química dos alimentos, etc. (texto 2)

Pode-se inferir que os alunos recém-chegados às universidades não têm a percepção do que sejam esses aspectos, pois a grande maioria citou, por exemplo, como aspecto interdisciplinar do texto 1 , apenas o trecho que citava as disciplinas Biologia, Física e Geologia. Uma possível justificativa para isso é o reflexo de uma formação do Ensino Médio ausente de ações interdisciplinares. Esse fato ressalta a importância das disciplinas de licenciatura, principalmente do estágio supervisionado, na formação desses alunos ingressantes que serão futuros professores.

Já os resultados das avaliações dos textos pelos alunos de semestres avançados das duas universidades mostraram que $71 \%$ dos alunos atribuíram conceito "bom". Um dos trechos destacados com maior frequência pelos alunos de semestres avançados foi:

A diabetes se caracteriza como uma doença ocasionada pelo acúmulo de glicose no sangue. A glicose é produto do metabolismo da substância sacarose (açúcar). Você já parou para pensar o que causa o acúmulo de glicose no sangue? Esse acúmulo pode ser causado de duas maneiras: 1 . Devido ao consumo excessivo de alimentos ricos em açúcares, carboidratos ou mesmo bebidas alcoólicas, associados a uma vida sedentária. 2. Em função da não produção ou produção insuficiente de insulina pelo organismo, impedindo o metabolismo da glicose.

Esses resultados são um indicativo de que os textos 
produzidos possibilitam o diálogo e integração entre diferentes áreas, de modo que o objeto de estudo possa ser abordado em diversas perspectivas.

Sendo assim, na perspectiva de formação inicial de professores, espera-se que o uso do material produzido possibilite aos licenciandos a experiência de desenvolvimento de atividades com características interdisciplinares, contribuindo assim para a superação da compartimentação dos saberes.

\section{Avaliação dos alunos quanto à utilização de Textos de Divulgação Científica no Ensino}

A Divulgação Científica é considerada essencial para o ensino de Ciências e, por isso, torna-se um aspecto indissociável da formação do professor. Nessa perspectiva, julgamos importante conhecer a visão dos alunos sobre os Textos de Divulgação Científica enquanto recurso didático em situações de ensino escolar, a fim de dar voz ao que se tem discutido na licenciatura sobre essa temática. Sendo assim, os pontos avaliados pelos alunos nos permitiram elucidar as suas opiniões sobre qual seria o espaço da Divulgação Científica no ensino formal.

Esse momento da pesquisa teve como objetivo identificar a percepção dos alunos quanto ao uso de Textos de Divulgação Científica no ensino. Ressalta-se que essa parte do questionário foi destinada apenas para os alunos de semestres avançados, já que estes se encontram imersos na prática docente através de disciplinas e de projetos, bem como de estágios supervisionados vivenciados.

Os critérios estabelecidos para que os alunos avaliassem o uso dos TDC no ensino foram: permitem esclarecer fenômenos do dia a dia; contribuem para a compreensão da Ciência; permitem análise de riscos/benefícios da aplicação dos conhecimentos científicos; permitem a inserção de novas abordagens e temáticas nas aulas de ciências; desenvolvem o gosto pela leitura; complementam o livro didático; aumentam o interesse dos alunos pela Ciência; promovem a popularização da ciência; melhor serem aplicados em sala de aula da educação básica/melhor serem aplicados em sala de aula no ensino superior.

Os resultados para cada categoria acima mencionada podem ser visualizados nas Figuras 1 e 2 . Um ponto a ser observado nessas figuras é a percepção dos licenciandos em relação ao uso do TDC no ensino. Do total de alunos, apenas $25 \%$ atribuiu a nota máxima para o uso no ensino superior. Esse percentual indica que ainda são poucos os alunos que vislumbram o uso desse material como recurso didático para os cursos de formação. Isso pode ser reflexo do próprio contexto da formação inicial. Strack et al. (2009, p.437), em sua pesquisa relacionada às percepções de professores de ensino superior sobre a literatura de divulgação científica, indicam que a Divulgação Científica é "valorizada no nível superior somente como um veículo de informação científica, mas não de formação científica". Além disso, indica a dificuldade de alguns professores quanto à utilização da literatura de Divulgação Científica como recurso didático. Dessa forma, a formação inicial parece ainda insistir em uma concepção pragmática de currículo, na qual os métodos de ensino são pautados, muitas vezes, somente no livro didático. Possivelmente, isso é um reflexo da concepção dos licenciandos em relação às estratégias de ensino para o nível superior envolvendo os TDC, bem como das lacunas de apropriação desse recurso didático às suas futuras aulas.

No seu conjunto, os resultados parecem demonstrar o caráter crítico/reflexivo dos alunos quanto ao uso de TDC no ensino. Observou-se que um grande percentual desses estudantes apresenta uma visão otimista a esse respeito, deixando claro suas percepções em relação à abordagem no Texto de Divulgação Científica para além do conteúdo específico.

Se, por um lado, os licenciandos conseguem perceber as potencialidades didáticas de Textos de Divulgação Científica, por outro, enfatiza-se a importância do uso desses

\section{O uso de TDC no ensino}

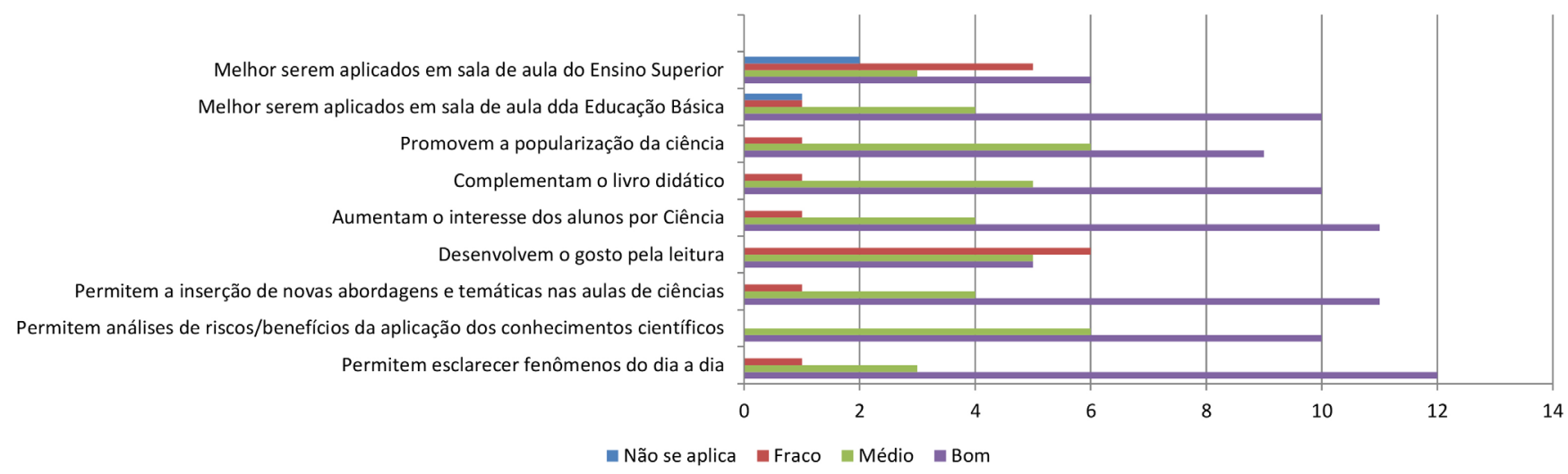

Figura 2: Percepção dos alunos de semestres avançados da Universidade B quanto ao uso de TDC no ensino 


\section{O uso de TDC no ensino}

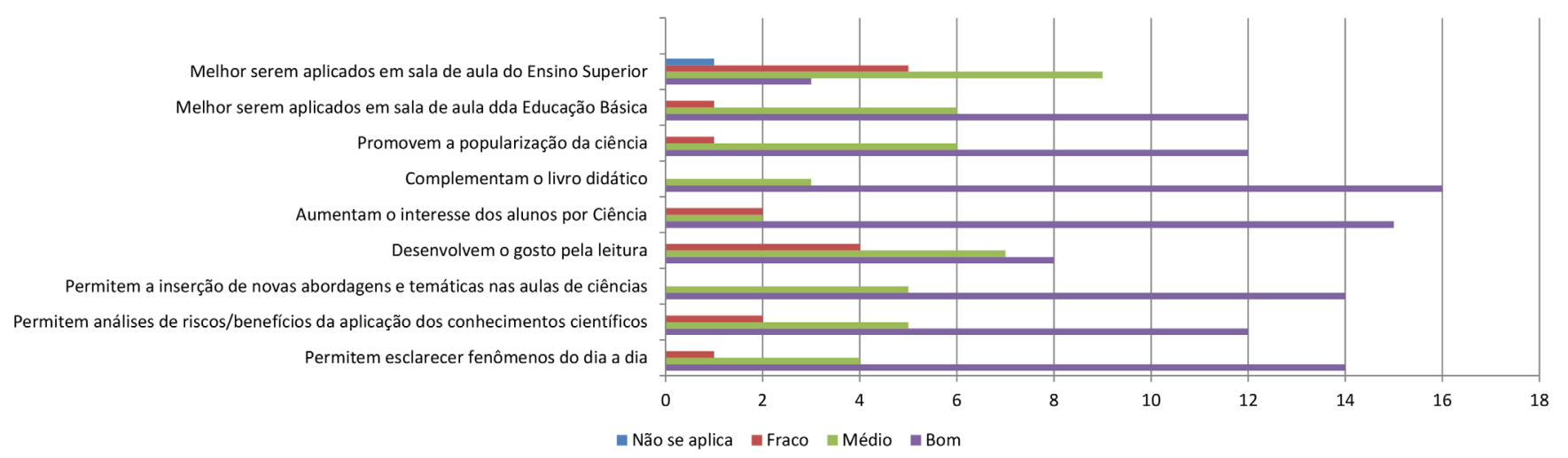

Figura 3: Percepção dos alunos de semestres avançados da Universidade A quanto ao uso de TDC no ensino

textos no processo de formação desses estudantes. Não basta apenas a percepção dos alunos relativa às potencialidades dessa estratégia didática: faz-se necessário que as questões teóricas epistemológicas e metodológicas sobre o uso de TDC no ensino sejam inseridas no espaço de formação inicial. A utilização desse material sem planejamento não fará sentido, pois o objetivo é torná-lo uma ferramenta de ensino-aprendizagem.

\section{CONSIDERAÇÕES FINAIS}

As considerações aqui construídas não são conclusivas, mas buscam o encaminhamento e perspectivas de continuidade da inserção da Divulgação Científica no ensino.

De modo geral, os resultados obtidos indicam que o objetivo pretendido foi alcançado, ou seja, conseguimos produzir o material de modo a contemplar as categorias que caracterizam os textos de Divulgação Científica com propósito educacional. A contribuição dessa pesquisa se pauta em fornecer eixos norteadores para a redação de Textos de Divulgação Científica especificamente para o ensino formal. Além disso, identificar as percepções que têm os alunos em processo de formação docente quanto ao uso de TDC, de modo que, a partir delas, as licenciaturas possam despertar para a inserção de práticas que privilegiem a produção de textos de divulgação da ciência. Adicionalmente, que as disciplinas que contemplam os aspectos formativos do licenciando, insiram em seu contexto discussões teóricas, de natureza epistemológica, a respeito de TDC como possível material didático a ser utilizado em práticas futuras desses alunos em formação. Se os próprios alunos reconhecem as potencialidades didáticas do TDC, por que não aprofundar as questões relacionadas à sua produção e ao seu uso pelos licenciandos quando em exercício?

Algumas categorias apresentaram dificuldades de serem avaliadas como, por exemplo, a natureza da ciência e relação fenômeno-teoria. As avaliações dos alunos apontaram suas próprias deficiências sobre essas temáticas. Essa afirmação é baseada nos resultados que demonstraram que os alunos não conseguiram justificar suas respostas utilizando informações do texto. Logo, os resultados corroboraram pesquisas apresentadas na literatura quanto às lacunas na formação inicial de professores referentes à natureza da ciência e à experimentação. Isso configura a necessidade de discussão explícita desses aspectos em cursos de formação de professores, bem como de reflexões sobre a prática docente e o currículo de formação de professores de ciências.

A postura crítica dos alunos indica a viabilidade do uso do material no ensino formal, corroborando, assim, ideias já levantas por outros pesquisadores da área. Entretanto, entende-se também que a validação dessas funções depende de como elas vêm sendo tratadas, tanto na formação inicial como na formação continuada dos professores.

Visando contribuir para as futuras práticas docentes dos estudantes, propomos que, nas disciplinas do estágio supervisionado, seja valorizada a produção e utilização desses materiais no plano de aula da regência, já que os próprios licenciandos reconhecem a potencialidade desse uso. Para isso, torna-se necessária a inserção de debates, nessa disciplina, sobre a potencialidade dos Textos de Divulgação Científica como apoio ao ensino formal. Esses debates devem aprofundar discussões sobre o que é um TDC, sobre o seu caráter educativo/formativo, bem como traçar estratégias de uso que valorizem o seu potencial.

Os textos foram escritos pensando em alunos do Ensino Médio, mas se os professores não compreendem aonde se deseja chegar, nem as possibilidades que potencialmente tem o material didático, ele chega à sala de aula sem contribuir para o processo ensino-aprendizagem. Logo, a formação inicial de professores de Química compartilha da responsabilidade de propiciar aos alunos (futuros professores) a experiência de se trabalhar com os textos de divulgação da Ciência, visto que, para que ele seja material educacional, precisa ser compreendido em sua essência pelo professor que irá usá-lo como estratégia didática. Além disso, a experiência que o aluno adquire com o uso desse material refletirá na 
forma como ele vai atuar futuramente. Por fim, entende-se ser necessário que o professor experimente enquanto aluno aquilo que utilizará com seus próprios alunos.

Como perspectiva de continuidade, espera-se que estas últimas considerações da pesquisa direcionem o olhar do professor para novas possibilidades de ensino, permitindo a ele reconfigurar a sala de aula. Além disso, o uso de Textos de Divulgação Científica em uma perspectiva investigativa e metodológica, de modo que funcionem como elementos motivadores e estruturadores da aula, vem sendo idealizado para nossas pesquisas futuras.

\section{REFERÊNCIAS}

BAKHTIN, M. Marxismo e Filosofia da Linguagem. 12 a ed. São Paulo: Hucitec, 2006.

BUENO, W. C. Jornalismo ambiental: explorando além do conceito. In: Girardi,I. M. T. Girardi; Schwaab, R. T. (Org.). Jornalismo ambiental: desafios e reflexões. Porto Alegre: Dom Quixote, 2008, p. 105-118.

CARNEIRO, M. H. S. Por que divulgar o conhecimento científico e tecnológico? Revista Virtual de Gestão de Iniciativas Sociais, edição especial, p. 29-33, março de 2009. Disponível em: www.ltds.uj.br/ gis/porque_divulgar.htmfr Acesso em: 01 de maio de 2016.

CINI, M. O paraíso perdido. Ciência Hoje, v.23, n.138, p.8-11, 1998.

DIANOVSKY, M. T.;WINK, D. J. Student learning through journal writing in a general education chemistry course for pre-elementary education majors. Science Education, v. 96, n.3, p.369-571, 2012.

DIAS, R. H. A.; ALMEIDA, M .J. P. M. Repetição em interpretações de licenciandos em Física ao lerem as revistas Ciência Hoje e Pesquisa Fapesp. Ensaio- Pesquisa em Educação em Ciências, v. 12, n. 3, p. 51-64, 2010.

ESTRADA, J. C. O. Educación y Divulgación de la Ciencia: tendendo puentes hacia la alfabetización científica. Revista Eureka sobre Enseñanza y Divulgación de las Ciencias, v. 8, n .2, 137-148, 2011.

FERREIRA, L. N. A.; QUEIROZ, S. L. Perguntas elaboradas por graduandos em Química a partir da leitura de textos de divulgação científica. Revista Brasileira de Pesquisa em Educação em Ciências, v.12, n.1, p. 139-160, 2012.

FERREIRA, L. N. A.; QUEIROZ, S. L. Autoria no ensino de química: análise de textos escritos por alunos de graduação. Ciência \& Educação, v.17, n.3, p.541-558, 2011.

FILHO, E. B.; FIORUCCI, A. R.; CHIMENEZ, T. A.; WONDRACEK, M. H., P.; SILVA, W. R.; BOTEGA, B. S. In: $57^{\text {a }}$ Reunião Anual da SBPC, 2005. Anais da 57 Reunião Anual da SBPC, 2005.

FLECK, L. La genesis y el desarollo de um hecho científico. Madrid: Alianza Editorial, 1986.

FREIRE, P. Pedagogia do Oprimido. Rio de Janeiro: Paz e Terra, 2005. GOMES, V.B.; SILVA, L.L; SILVA, R. R.; MACHADO, P. F. L. Avaliação do impacto de visitas e palestras de divulgação cientifica em alunos do ensino médio visitantes ao campus da Universidade de Brasília. In: Atas do VIII Encontro Nacional de Pesquisa em
Educação em Ciências, 2011. Campinas, SP. Disponível em: http:// www.nutes.ufrj.br/abrapec/viiienpec/resumos/R0233-1.pdf Acesso em: 01 de maio de 2016.

HARRES, J. B. S. Uma revisão de pesquisas nas concepções de professores sobre a natureza da ciência e suas implicações para o ensino. Investigações em Ensino de Ciências, v.4, n.3, p. 1-17, 1999.

KOSMINSKY, L.; GIORDAN, M. Visões sobre Ciências e sobre o Cientista entre Estudantes do Ensino Médio. Química Nova na Escola, v. 15, p. 11-18, 2002.

KREINZ, G.; PAVAN, C.; MARCONDES FILHO, C. Feiras de Reis: cem anos de divulgação científica no Brasil. v. 10. São Paulo: Publicações NJR, 2007.

LUDKE, M.; ANDRÉ, M. E. D. A. Pesquisa em educação: abordagens qualitativas. São Paulo: E.P.U., 1986, p. $11-48$.

LIMA, A. A.; NÚÑEZ, I. B. Reflexões acerca da natureza do conhecimento químico: uma investigação na formação inicial de professores de química. Revista Brasileira em Educação em Ciências, v. 11, n. 3, p. 209-229, 2011.

MOREIRA, I. C. A inclusão social e a popularização da ciência e tecnologia no Brasil. Inclusão Social, v. 01, n. 2, p 11-16, 2006.

MORTIMER, E. F.; SCOTT, P. Atividade discursiva nas salas de aula de ciências: uma ferramenta sociocultural para analisar e planejar o ensino. Investigações em Ensino de Ciências, v. 7, n. 3, p. 283-306, 2002.

NASCIMENTO, T. G. Contribuições da análise do discurso e da epistemologia de Fleck para a compreensão da divulgação científica e sua introdução em aulas de ciências. Ensaio-Pesquisa em Educação em Ciência, v. 7, n. 2, p. 1-18, 2005.

NASCIMENTO, T. G.; CASSIANI, S. Leituras de divulgação científica por licenciandos em Ciências Biológicas. Revista Electrónica de Enseñanza de las Ciencias, v. 8, n. 2, p.745-769, 2009.

NASCIMENTO, T. G.; REZENDE JR., M. F. A produção de divulgação científica na área de educação em ciência: referenciais teóricos e principais temáticas. Investigação em Ensino de Ciências, v. 15, n. 1, p. 97-120, 2010.

NASCIMENTO, T. G.; REZENDE JR., M. F. A. produção de textos de divulgação científica na formação inicial de licenciandos em ciências naturais. Revista Brasileira de Pesquisa em Educação em Ciências, v. 10, n. 1, p. 1- 22, 2010.

PALCHA, S. L.; OLIVEIRA, O.B. Discursos sobre leitura e Ensino de Evolução na Formação de Professores de Ciências. Investigações em Ensino de Ciências, v. 14, n. 1, p.125-149, 2014.

PEREIRA, C. L. N.; SILVA, R. R. A História da Ciência e o ensino de ciências. Revista Virtual de Gestão de Iniciativas Sociais, Edição especial, março de 2009. Disponível em: http://www.ltds.ufrj.br/ gis/a_historia.htm Acesso em: 01 de maio de 2016.

PÉREZ, C. MOLINI, A. M. V. Consideraciones generales sobre la alfabetización científica em los museos de la ciencia como espacios educativos no formales. Revista Electrónica de Enseñanza de las Ciencias, v. 3, n. 3, 2004.

PIMENTA, M.; GOUVÊA, G. Imagens na divulgação científica em jornais de grande circulação no Brasil. In: Anais do VII Encontro Nacional de Pesquisa em Educação em Ciências, Florianópolis, SC, 
novembro, 2009. Disponível em: http://posgrad.fae.ufmg.br/posgrad/ viienpec/pdfs/237.pdf Acesso em: 01 de maio de 2016.

PPGEC-UnB. Propostas de Ação Profissional. Disponível em: http:// ppgec.unb.br/images/sampledata/dissertacoes/2012/proposicao/ verenna_barbosa_gomes.pdf Acesso em 01 de maio de 2016.

QUADROS, A. L; SILVA, D. C; SILVA, F. C. Formulação de questões a partir da leitura de um texto: desempenho dos estudantes de licenciatura em Química da modalidade à distância. EnsaioPesquisa em Educação em Ciências, v. 13, n. 1, p. 43-56, 2011.

RIBEIRO, R. A; KAWAMURA, M. R. A ciência em diferentes vozes: uma análise de textos de divulgação científica. In: Atas do V Encontro Nacional de Pesquisa em Educação em Ciências, 2005, Bauru, SP. Disponível em: http://www.nutes.ufrj.br/abrapec/venpec/ conteudo/artigos/3/pdf/p803.pdf Acesso em: 01 de maio de 2016.

RIBEIRO, N. A.; MUNFORD, D; PERNA, G. P. A. Experiências de leitura em Ciências da Natureza na Educação de Jovens e Adultos: um estudo das práticas de professores em formação inicial. Revista Brasileira de Pesquisa em Educação em Ciências, v. 12, n. 2, p. 129-151, 2012.

SANTOS, W. L; SCHNETZLER, R. P. Educação em Química: compromisso com a cidadania. Ijuí: Unijuí, 2003.

SCHEID, N. M. J.; PERSICH, G. D. O. e KRAUSE, J. C. Concepção de natureza da ciência e a educação científica na formação inicial. In: VII Encontro Nacional de Pesquisa em Educação em Ciências, v.1, 2009, Florianópolis. Anais... Belo Horizonte: Editora da UFMG, 2009. Disponível em: http://posgrad.fae.ufmg.br/posgrad/viienpec/ pdfs/552.pdf Acesso em: 01 de maio de 2016.
SILVA, B. V. C. A natureza da Ciência pelos alunos do ensino médio: um estudo exploratório. Latin American Journal of Physics Education, v. 4, n. 3, p. 620-627, 2010.

SILVA, R. R.; MACHADO, P. F. L.; TUNES, E. Experimentar sem medo de errar. In: SANTOS, W. L. P.; MALDANER, O. A. (Org). Ensino de Química em Foco. Ijuí: Unijuí, 2010, p. 236-261.

SOARES, G J.; XAVIER, M, H, F, B. Visões de Ciências dos Alunos Ingressantes no Curso de Química da UFG. Atas do XIV ENEQ, Curitiba, PR, 2008. Disponível em: http://www.quimica.ufpr.br/ eduquim/eneq2008/resumos/R0829-1.pdf Acesso em: 01 de maio e 2016.

SOUZA, J. A. C.; GIERING, M. E. O infográfico: a palavra e a imagem em textos da divulgação científica midiática. Linguagem \& Ensino, v. 13, n. 2, p. 295-317, 2010.

STRACK, R.; LOGUERCIO, R.; DEL PINO, J. C. Percepções de professores de ensino superior sobre a literatura de divulgação científica. Ciência e Educação, v. 15, n. 2, p. 425-442, 2009.

TERRA, L.; LARENTINS, A. L.; ATELlA, G. C.; CALDAS, L. A; RIBEIRO, M. G. L. Identificação de obstáculos epistemológicos em um artigo de divulgação científica - entraves na formação de professores de ciências. Revista Electrónica de Enseñanza de las Ciencias, v. 13, n. 3, p. 318-333, 2014.

ZANOTELLO, M.; ALMEIDA, M. J. P. M. Leitura de um texto de divulgação científica em uma disciplina de física básica na educação superior. Ensaio- Pesquisa em Educação em Ciências, v. 15, n. 3, p. 113-130, 2013. 